\title{
Organization Performance Model based on Evolution of Information System: Knowledge Sharing Perspective
}

\author{
Junling Xu \\ The management school of the Central China Normal University, \\ Wuhan, China \\ angelaxu03@126.com
}

\begin{abstract}
Information systems are advancing, even though the logic of complementarity effect is still persisting, few researches discussed how information technology boosts up multilateral cooperation effect and how information technology come into being benefit through indirect network interlink. The paper will construct a model where knowledge sharing creates indirect relation value based on information system capabilities.
\end{abstract}

\section{Introduction}

From a review of IS literature we identified three broad stages along which the business purpose of Information technology has evolved. During the first stage, in the past, IT was deployed largely to improve intra-organizational efficiency and effectiveness. The IS functionality was not only transaction oriented but also enabled communication between groups, decision makers and facilitated exectives'information search. Thus, other than transaction-processing systems, research on other IS such as decision support systems (DSS), group decision support systems, etc., was also conducted. Significant amount of research in the past two decades was focused at the intra-organizational level. In the second stage, deployment of IT investments to support business activity at the interorganizational level was concurrent with the development of sophisticated IT products, which is termed as inter-organizational systems (IOS). IS literature later focused on electronic data interchange (EDI). EDI is considered to be an inflexible and transaction oriented proprietary technology where investors face large switching costs. With standardization of IS, especially with the Internet technology, more flexible Its constitute IOSs. These offer functionality ranging from automated, repetitive transactions to more collaborative and customized workplace technologies. Thus, currently investments in IOSs are aimed to not only save transaction costs, but also to enable better knowledge sharing and learning between two or more organizations. In the third stage, its are being deployed for a higher order function-that of managing interactions between different business relationships as against interactions at the dyadic level. By enabling interactions between entities spread across two or more firms, these systems such as e-markets, knowledge management systems, etc., give rise to scope or scale economies. As a result, organizations are able to offer better products to customers or reuse existing knowledge. IOSs in the stage are playing an important role in sustaining newer forms of organizational networks. This can 
guide investment in emerging technologies to not only improve benefits from relationships at a dyadic level but also at the business network level.

IT is necessary to consider the production function of information technology not limit to transact cost view while taking account of information technology functions, which helps to discuss IT operation value in organization networks based on knowledge and resource logic[1]. even though the logic of complementarity effect is still persisting, few researches discussed how information technology boosts up multilateral cooperation effect and how information technology come into being benefit through indirect network interlink. The paper will construct a model where knowledge sharing creates indirect relation value based on information system capabilities.

\section{Relational Value in Inter-Organizational Networks}

Increasing attention is focused on the study of business networks as organizational forms distinct from markets or firms. This is because value addition is often done jointly by business partners rather than by individual firms transacting at arms-length through market mechanisms. However, the network paradigm suggests that for organizations embedded in multiple business relationships, value can accrue because of indirect connections with other organizations through a common business entity. There are interdependencies even between those actors who are not transacting directly but may have common partners, suppliers or customers. There has been growing recognition of such interdependence effects in the literature. In a network consisting of collaborative relationships for product design and development, Eriksson et al, note that" the understanding of how technology adaptations in one relationship are contingent on adaptations in another is a key to understanding the dynamic of knowledge transfer between business relationships in a network"[4].An example of interdependencies in a business network is when a focal organization's relationship with one supplier contributes to better serving the focal organization's customers. For example in the case of Ericsson and Tokyo Digital Phone, Ericsson had to establish ties with a local Japanese firm Toshiba in order to gain necessary country-specific expertise and linguistic competence. The success of the project between them depended considerably on the success of the collaboration between Ericsson and Toshiba. The importance of information technology to manage business activities in a network context is increasingly important for good performance. We propose that as such interdependencies between firms increase, it is fruitful to explore how IS capabilities can contribute to value in business networks.

The potential to advance the theory on the value of IS in business networks can be realized by a deeper examination of the literature on value creation in business relationships. The resource-based view contends that competitive advantage results when a single firm delivers value using sustainable inimitable resources possessed and controlled by it. Whereas, the relational view suggests that"(dis)advantages of an individual firm are often linked to the (dis)advantages of the network of relationships within which a firm is embedded". This view refers to relational value as value that a firm derives by virtue of a relationship with a specific partner as opposed to relationship with alternative potential partners. 
On reviewing the nature of IOSs under study and the related IS capabilities we find that IS research on business value has two main limitations. First, the theoretical bases for defining business value have predominantly a transaction cost econmomics viewpoint.Second,business value-related IS research has restricted the conception of business value at dyadic level and has not advanced it to the network level. In the next part, we develop the research model with IS capabilities as the independent variables affecting indirect relational value. We argue that knowledge sharing intermediates the effect of IS capabilities on indirect relational value.

\section{Knowledge Sharing Based on Information System}

\section{Capabilities}

IS capabilities provide such Bus, the enterprises and their business partners, with a common platform for sharing knowledge. Literature on IT infrastructure identifies two dimensions, reach and range as leading to increased synergies across business units. However, there are few empirical studies they attempt to establish a theoretical link between IS capabilities and knowledge sharing. Therefore, we shall now conceptualize IS capabilities in terms of its three distinct facets, IS integration, IS range and IS reach. For understanding how IS integration may lead to higher knowledge sharing, we argue using the absorptive capacity viewpoint [7]. We propose that IS integration of a focal BU wth other Bus represents the absorptive capacity of the focal Bus towards these other Bus. Higher IS range implies a higher extent to which the IT portfolio represents codified rules for performing the business activities and a higher extent to which employees exposed to the IT portfolio. Thus, higher IS range can be viewed as enhancing the cognitive dimension of social capital within the enterprises. IS range can also indirectly contribute to knowledge sharing. Higher IS reach implies a richer medial for employee-to-employee connectivity and thus may enhance transfer for knowledge.

The theory on absorptive capacity views internal knowledge structures in firms as critical to the absorption, assimilation, enhancement, and application of useful external knowledge. Dyer and Singh [3] term this as partner-specific absorptive capacity. This means that combinative capabilities are nurtured within network links between organizations. This enables business units to acquire and process external knowledge. Having integrated ISs with well-defined data and application standards enables organizations to share richer knowledge across their business relationships [5]. Currently, as enterprises are implementing increasingly sophisticated IT applications to conduct business with other enterprises, higher IS integration represents a significant amount of encoding of inter-firm business rules. Thus, though empirical studies investigating the positive impact of integration on knowledge sharing are limited, there is significant qualitative evidence.

IS range and IS integration need not be considered as exclusive to an IT component also. Each IT application offers both dimensions of IS capabilities, IS range and IS integration. IS range is that which automates business activities, i.e., internal operations. Therefore, the set of IT applications and databases such as supply chain management software, CRM, etc., all are primarily designed to 
perform well-defined business functions. These components may measure high on IS range dimension. The second dimension is integration capability, i.e., extent of integration of applications and databases across various organizational units. This may be achieved through integration products such as middleware or web services. Thus, integration products may be viewed as measuring high on IS integration dimension but low on Is range dimension. There is not much empirical support in literature on whether IS range can lead to higher knowledge sharing. We theorize this link based on the absorptive capacity [7] and social capital viewpoints. A higher IS range signifies a higher level of absorptive capacity that helps the employees to assimilate internal information better and generate newer insights into its business activities. Having a greater IS range implies that the employees have access to rich and in-depth knowledge about their business activities. It also implies that an implicit, rich knowledge structure is imposed on the organization, which can be used to process and share knowledge and thus to create higher value. Further, when all employees have wide access to the software applications to perform their work, they develop a common cognitive frame of reference and a shared representation of the environment and business activity. This is similar to the "Cognitive dimension" of social capital that facilitates creation of intellectual capital. Therefore, higher IS range in terms of access to employees should also lead to higher knowledge sharing.

Reach refers to the extent to which employees within the ecosystem of multiple organizations are electronically connected with one another. Greater reach is characterized by increase connectivity among individuals and groups. Whereas IS range repents the sophistication of IT applications in terms of automating or facilitating internal operations in a business entity, IS reach captures the extent to which the employee-to-employee communications is supported across business unit boundaries. Dedicated, real-time, high-bandwidth information infrastructure provides a richer medium through which more complex and useful information can be transmitted. There is significant empirical support for positive effect in theoretical literature. Media richness theory supports the view that the ability of IT infrastructure to facilitate richer communication across business entities is likely to lead to greater knowledge sharing. Empirical studies found that connectivity offered by information technology is highly related to richer and more effective information sharing[6].

Though both IS integration and reach are facets of the IS capabilities of enterprises interacting with other enterprises, the two elements are distinct from a conceptual standpoint .IS reach can be viewed as facilitating unstructured coordination, while IS integration facilitates encoded, structured coordination across business units (Bus).

\section{Knowledge Sharing and Indirect Relational Value}

Inter-organizational relationship literature proposes value antecedents such as knowledge sharing routines, relation-specific assets, trust, etc., that may lead to higher relational value. Significant qualitative and empirical studies strongly point to ability of IT to enhance information exchange and organizational learning. Therefore, we extend IS literature to examine how knowledge sharing may mediate the impact of IT on business value. Our overall proposition is that knowledge sharing moderates the impact of IS capabilities on indirect relational 
value. Prior literature richly describes how knowledge sharing is a potentially significant antecedent of relational value. For example, it is argued that a production network with superior knowledge-transfer mechanism among users, suppliers and manufacturers will be able to "out innovate" production networks with less effective knowledge-sharing mechanisms. Knowledge sharing routines refer to a pattern of inter-firm interactions that permits the transfer, recombination or creation of specialized knowledge [3]. Based on benefits such as improved innovation, knowledge sharing routines has been proposed as one of the antecedents of relational rents. Empirical literature also strongly supports the linkage between knowledge sharing and business unit performance.

We define indirect relational value as the extent to which a focal business entity's relationships with other entities, benefits the focal entity's overall business network. A related construct called business network connection refers to the influence that relationships with third parties have upon the focal relationship. A higher business network connection was hypothesized to eventually lead to higher value creation in a focal relationship. Unlike this dyadic level notion of relational value, our definition of indirect relational value views a relationship as a transmitter of benefits. Indirect relational value is a predominant outcome of business network relationships according to at least two streams of literature on organizational theory, i.e., social exchange theory and social networks. Social exchange theory suggests that in a context where organizations conduct and maintain a configuration of ongoing relationships, organizations may benefit from one relationship to the extent that it enhances the other relationships. This can happen because knowledge and solutions from a focal relationship can be re-applied to other relationships and vice versa. Social network analysis treats business entities as linked in a network. Benefits accrue to these entities depending on their structural position in the network. Since there is more than one way in which a structural position yields benefits, it is critical to understand the particular network mechanism that yields the benefits to a network entity [2]. These different types of mechanisms are closure, brokerage, prominence, contagion, etc. For example, if a network entity brokers information between multiple network entities and thus gains arbitrage, the member is said to accrue network benefits through a brokerage mechanism. Similarly if a central member inn a supply chain maintains rich and efficient relationships with other members, the central member has access to the knowledge and expertise of its partners, i.e., a closure mechanism yields benefits to the network entity. In our research context we are not interested in the brokerage benefits accruing to many particular network member but in the benefits resulting from intense, rich interactions with the network partners. These benefits could be access to new customers, acquisition of knowledge and expertise and improving coordination to improve efficiency of business operations.

The notion of indirect relational value is also consistent with the economies of scope argument in a production context. Here an organization can save on costs by reapplying its existing resources to the activities performed in other parts of the organization. Such resources are broadly labor and capital. However, in the $\mathrm{B} 2 \mathrm{~B}$ context, economies of scope can result as the Bus within the organizations learn to reapply the knowledge of the other Bus in order to derive cross-selling benefits or higher customer satisfaction. This results in faster customer acquisition or higher customer loyalty. The overall result is higher indirect relational value derived by an organization from its portfolio of 
relationships. Recent IS literature also indicates the benefits of transporting knowledge acquired during a particular transaction to other business activities by using knowledge management systems. Theoretical literature on alliances strongly support that knowledge sharing is positively related to indirect relational value. In the social network method, all firms in the sample are connected to each other through network linkages.

The literature review exceeds knowledge sharing and value creation relativity, moreover, the relationship of knowledge sharing based on IS capabilities dimensions are explored and workflow, society ties are also been taken in account. In the final, the paper discusses the process knowledge sharing accrues relational value. This transfer process can be seen in figure 1 . Using the theoretical fondation offered by knowledge-based theories, we argue that knowledge sharing intermediates the effect of IS capabilities on indirect relational value.

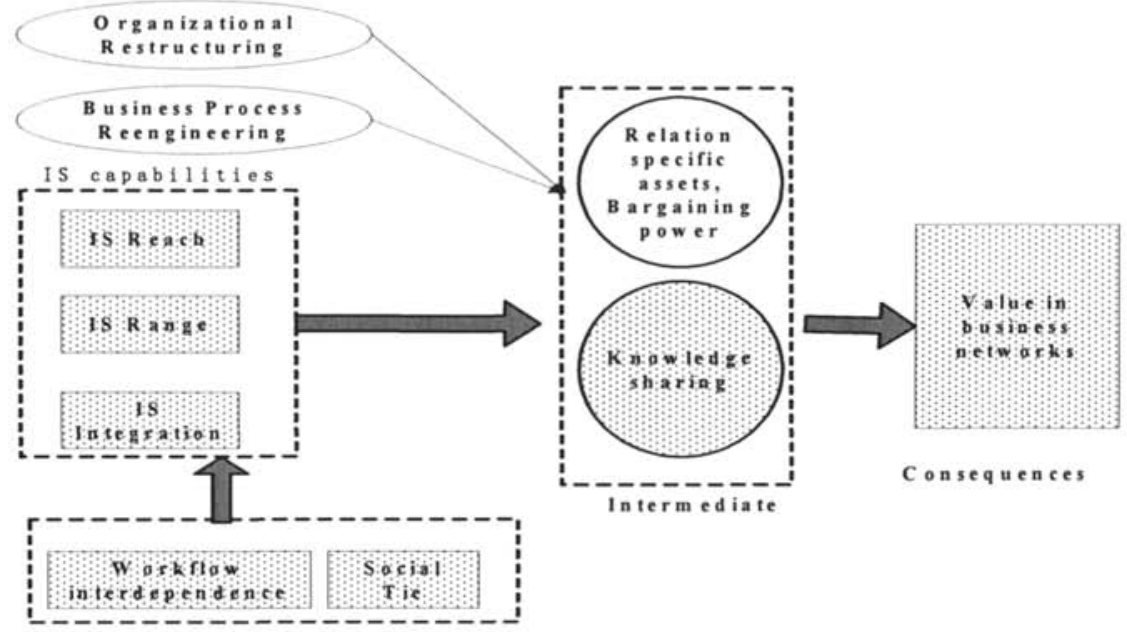

Figure1 Relational Value Model based on IS Capabilities

\section{References}

1. Amit, R., and Zott,C."Value creation in e-business". Strategic Management Journal, 2001, 22(6): 493-520

2. Burt.R.S.The network structure of social capital.In:Research in organizational behavior, B.M.Staw,JAI Press, Greenwich,CT,2000

3. Dyer, J.H,Singh,H. The relational view:Cooperative strategy and sourses of interorganizational competitive advantage. The Academy of Management review, 1998

4. Eriksson, K., and Hohenthal,J.The transferability of knowledge in business network relationships.In:Business Network Learning,J.Johanson,Elsevier Science,New York,2001.

5. Markus,K.E."Developing consensus on firm competencies and capabilities". Academy of Management Executive 10,2000:40-51

6. Staples,S.D and Jarvenpaa,S.L.Using electronic media for information sharing activities:A replication and extension,ICIS, New Orleans, 2001

7. Zahra,S.A.,and George,G.Absorptive capacity: "A review,reconceptualization and extension". Academy of management review,2002,27(2):185-203 